\title{
Cephalad migration of intrathecal clonidine in an infant undergoing bilateral herniorrhaphy
}

\author{
S. V. Rakesh, MBBS · Subramanyam Rajeev, MD • \\ Yatindra Kumar Batra, MD - Katragadda L. N. Rao, MCh
}

Received: 24 April 2009/Accepted: 12 May 2009/Published online: 28 May 2009

(c) Canadian Anesthesiologists' Society 2009

\section{To the Editor,}

Intrathecal clonidine is often added to bupivacaine to prolong the duration of spinal anesthesia in the pediatric population. ${ }^{1}$ However, there may be important central nervous system (CNS) effects due to cephalad spread of clonidine following intrathecal administration of a clonidine-bupivacaine mixture.

A $31 / 2$-month-old full-term male infant (51 weeks postconception) weighing $5 \mathrm{~kg}$ was scheduled for bilateral inguinal hernia repair. Preoperative evaluation was unremarkable, except for the presence of an asymptomatic atrial septal defect measuring $4.5 \mathrm{~mm}$ in diameter. After obtaining written parental consent, the infant was sedated with propofol (10 mg bolus and infusion at $25 \mu \mathrm{g} \cdot \mathrm{kg}^{-1}$. $\min ^{-1}$ ). A lumbar puncture was performed using a $25 \mathrm{~mm}$, 25 G spinal needle (Beckton Dickinson, Madrid, Spain) with the patient in the left lateral position. Intrathecal clonidine $5 \mu \mathrm{g}$ and hyperbaric bupivacaine $2.5 \mathrm{mg}(0.5 \%)$ were administered in a volume of $0.53 \mathrm{~mL}$. The infant was then turned supine. The height of spinal block was T3 after five minutes. Within eight minutes, the infant was deeply sedated and propofol sedation was discontinued. However, the infant continued to be deeply sedated and lethargic, and there was flaccidity with no spontaneous movement of either upper limb. No clinically significant hypotension, bradycardia, or desaturation were observed, but the patient's respiratory efforts were inadequate with intermittent apneic episodes. Therefore, tracheal intubation was

S. V. Rakesh, MBBS · S. Rajeev, MD · Y. K. Batra, MD ( $₫)$.

K. L. N. Rao, MCh

Postgraduate Institute of Medical Education and Research, Chandigarh, India

e-mail: ykbatra@glide.net.in performed after administration of thiopental $10 \mathrm{mg} i v$, and anesthesia was maintained with sevoflurane and nitrous oxide. The duration of surgery was $62 \mathrm{~min}$. The inhalational agents were then discontinued, and the patient was transferred to the postanesthesia care unit where mechanical ventilation was maintained. Return of movement in the infant's upper limbs was first noted $7 \mathrm{hr}$ and $26 \mathrm{~min}$ after administration of spinal anesthesia, with complete recovery of motor function in all limbs $8 \mathrm{hr}$ after block administration. The trachea was then extubated. The first need for rescue analgesia was at $8 \mathrm{hr}$ and $17 \mathrm{~min}$. The patient was observed for $72 \mathrm{hr}$ in the step-down unit where no apneic episodes, desaturation, or hemodynamic instability were noted.

Intrathecal doses of bupivacaine $0.5 \mathrm{mg} \cdot \mathrm{kg}^{-1}$ and clonidine $1 \mu \mathrm{g} \cdot \mathrm{kg}^{-1}$, normally provide spinal blockade without adverse effects. ${ }^{1}$ The total volume given was $0.53 \mathrm{~mL}$ or approximately $0.1 \mathrm{~mL} \cdot \mathrm{kg}^{-1}$. In infants, volumes of up to $0.2 \mathrm{~mL} \cdot \mathrm{kg}^{-1}$ have been used without significant adverse effects. The flaccidity of limb muscles, prolonged sedation, and respiratory depression suggests the occurrence of CNS toxicity with clonidine. Such toxicity has been observed with various routes of administration of clonidine, including eye drops. ${ }^{2}$ Common clinical features of clonidine toxicity are variable and include somnolencelethargy (96\%), miosis (56\%), and respiratory depression (48\%), with treatment being mainly supportive. ${ }^{3}$ Children seem to be unusually sensitive to the depressant effects of clonidine. In this case, the intrathecally administered clonidine-bupivacaine mixture might have caused CNS toxicity due to cephalad spread of clonidine. As a result, CNS manifestations, such as somnolence, hypotonia, and respiratory depression, were produced without effects on other organ systems. On its own, a high level of spinal anesthesia produces sedation, but the block is expected to 
recede and resolve within $70-90 \mathrm{~min}$, contrary to the observations in the present case. ${ }^{4}$ The paradoxical breathing observed initially may have been due to high spinal anesthesia or to clonidine-induced respiratory depression. In a recent case report, ${ }^{5}$ an intrathecal clonidine-bupivacaine mixture produced a high spinal blockade lasting $90 \mathrm{~min}$. It is suggested that anesthesiologists exercise caution when using intrathecal $\alpha-2$ agonists with local anesthetics in infants. Routine use of intrathecal clonidine should be avoided until further randomized controlled trials or surveillance studies determine its safety and establish a clear indication for its use.

Conflicts of interest None declared.

\section{References}

1. Rochette A, Raux O, Troncin R, Dadure C, Verdier R, Capdevila $X$. Clonidine prolongs spinal anesthesia in newborns: a prospective dose-ranging study. Anesth Analg 2004; 98: 56-9.

2. Rangan $C$, Everson $G$, Cantrell $F L$. Central alpha-2 adrenergic eye drops: case series of 3 pediatric systemic poisonings. Pediatr Emerg Care 2008; 24: 167-9.

3. Wiley JF II, Wiley CC, Torrey SB, Henretig FM. Clonidine poisoning in young children. J Pediatr 1990; 116: 654-8.

4. Wright TE, Orr RJ, Haberkern CM, Walbergh EJ. Complications during spinal anesthesia in infants: high spinal blockade. Anesthesiology 1990; 73: 1290-2.

5. Aouad MT, Moukaddem F, Akel SR, Kanazi GE. Respiratory failure in a former preterm infant following high spinal anesthesia with bupivacaine and clonidine. Paediatr Anaesth 2008; 18: 1000-1. 